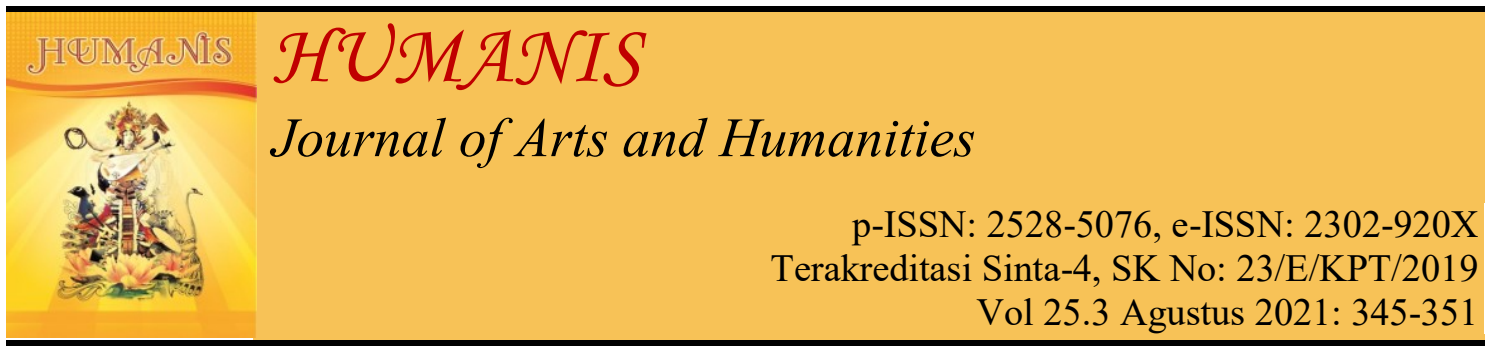

\title{
Geguritan Ni Sumala: Suatu Kajian Filologis
}

\section{Luh Gede Krismayanti, I Wayan Suteja, I Gde Nala Antara}

Universitas Udayana, Denpasar, Bali, Indonesia

Email korespondensi: luhgdkrismayanti@gmail.com, wynsuteja80@yahoo.com , nala.antara62@gmail.com

\begin{tabular}{|c|c|}
\hline Info Artikel & Abstract \\
\hline $\begin{array}{l}\text { Keywords: geguritan, text } \\
\text { criticism, text edition, } \\
\text { translation }\end{array}$ & $\begin{array}{l}\text { This study aims to obtain the text of Geguritan Ni Sumala which } \\
\text { approaaches the original. The data supply phase uses the } \\
\text { observation method and simak method helped by note taking } \\
\text { technique. Next, in data analysis phase using comparative } \\
\text { descriptive method, transliteration uses standard transliteration } \\
\text { method, following by a comparation of three texts through text } \\
\text { criticism, text edition using the legger method, the translation } \\
\text { uses combination literal translation and idiomatic translation. } \\
\text { In the stage of presenting the result of data analysis using } \\
\text { formal and informal method by deductive-inductive tecnique } \\
\text { also assisted by exposure, tables, and themes. The text edition is } \\
\text { complemented by criticism apparatus which is presented } \\
\text { separately and translation is also presented separately with the } \\
\text { source text. The result of this study are, from the three of GNS } \\
\text { manuscripts that have been compared through text criticism } \\
\text { there are some copy/write errors from each text such as } \\
\text { substitution, adition, omission, lakuna, interpolation, } \\
\text { ditography, transposition, and corrupt. By correcting the copy } \\
\text { error presented Geguritan Ni Sumala text which assumed to be } \\
\text { correct based on the evidence three of contained manuscripts. }\end{array}$ \\
\hline & Abstrak \\
\hline $\begin{array}{l}\text { Corresponding Author: Luh } \\
\text { Gede Krismayanti } \\
\text { Email: } \\
\text { luhgdkrismayanti@gmail.com }\end{array}$ & $\begin{array}{l}\text { Tujuan penelitian ini adalah untuk mendapatkan teks Geguritan } \\
\text { Ni Sumala yang mendekati aslinya. Tahap penyediaan data } \\
\text { menggunakan metode observasi dan metode simak dibantu } \\
\text { teknik catat. Selanjutnya, tahap analisis data menggunakan } \\
\text { metode deskriptif komparatif, transliterasi dengan metode } \\
\text { transliterasi standar, dilanjutkan dengan perbandingan ketiga } \\
\text { teks melalui kritik teks, edisi teks menggunakan metode } \\
\text { landasan (legger), terjemahan menggunakan metode kombinasi } \\
\text { terjemahan harfiah dan terjemahan idiomatis, disertai teknik }\end{array}$ \\
\hline $\begin{array}{l}\text { DOI: } \\
\text { https://doi.org/10.24843/JH.20 } \\
\text { 21.v25.i03.p11 }\end{array}$ & $\begin{array}{l}\text { terjemahan terpisah. Tahap penyajian hasil analisis data } \\
\text { menggunakan metode formal dan informal dengan teknik } \\
\text { deduktif-induktifjuga dibantu teknik paparan, tabel, dan stema. } \\
\text { Edisi teks dilengkapi dengan aparat kritik yang disajikan } \\
\text { terpisah dan terjemahan juga disajikan secara terpisah dengan } \\
\text { teks sumbernya. Hasil dari penelitian ini yaitu, dari ketiga } \\
\text { naskah GNS yang telah dibandingkan melalui kritik teks } \\
\text { terdapat beberapa kesalahan salin/tulis dari masing-masing } \\
\text { teks berupa substitusi, adisi, omisi, lakuna, interpolasi, } \\
\text { ditografi, transposisi, dan korup. Setelah memperbaiki } \\
\text { kesalahan salin/tulis disajikan teks Geguritan Ni Sumala yang } \\
\text { diasumsikan mendekati aslinya berdasarkan bukti dari ketiga } \\
\text { naskah. }\end{array}$ \\
\hline
\end{tabular}




\section{PENDAHULUAN}

Kesusastraan masih sangat berkembang pesat dalam kehidupan masyarakat Bali hingga saat ini. Menurut Tinggen (1982: 72), secara garis besar kesusastraan Bali dapat digolongkan menjadi dua yakni Kesusastraan Bali Tradisional atau yang lebih dikenal dengan Kesusastraan Bali Purwa dan Kesusastraan Bali Modern atau yang lebih dikenal dengan Kesusastraan Bali Anyar sesuai dengan khazanah kesusastraan Bali.

Geguritan di Bali juga bervariasi dalam menggunakan jumlah pupuh di dalam karya sastranya, ada yang memakai satu jenis pupuh. Contohnya Geguritan Linggar Petak hanya menggunakan pupuh Ginada dan Geguritan Sewagati hanya menggunakan pupuh Sinom. Sebagian besar geguritan juga menggunakan dua jenis pupuh atau lebih. Salah satu geguritan yang menggunakan dua pupuh adalah Geguritan Ni Sumala.

Ni Sumala dalam bentuk karya sastra geguritan merupakan salah satu warisan leluhur yang masih dijumpai keberadaan naskah dan teksnya hingga saat ini. Adapun bahasa yang digunakan dalam karya sastra ini adalah Bahasa Bali Kawi. Dilihat dari aturan padalingsa, geguritan ini menggunakan dua jenis pupuh yakni Pupuh Ginada sejumlah 187 bait dan Pupuh Adri sebanyak 33 bait. Sesuai dengan judulnya, tokoh utama dalam geguritan ini bernama Ni Sumala.

$\mathrm{Ni}$ Sumala sebagai bagian dari geguritan Bali memiliki varian teks dalam bentuk manuskrip yang tersebar di Pulau Bali. Banyaknya temuan naskah yang tersebar di masyarakat dan instansi pemerintah, memperkuat potensi penyebaran penyimpanan naskah Geguritan Ni Sumala di wilayah Bali.

Berkaitan dengan penelitian ini, penulis menemukan lima buah naskah
Geguritan Ni Sumala. Dua buah naskah tersimpan di Kantor Dokumentasi Budaya Bali termasuk satu salinan naskah dalam huruf Latin. Satu naskah lontar beserta satu salinan naskah huruf Latin ditemukan di UPTD Gedong Kirtya Singaraja serta satu buah naskah lontar yang tersimpan di Pusat Kajian Lontar Universitas Udayana.

Berbagai varian naskah dari Geguritan Ni Sumala memerlukan suatu pengkajian khusus untuk memurnikan teks ke bentuk mendekati aslinya. Diperlukan ilmu filologi sebagai kajian yang tepat untuk permasalahan ini. Baried (1985: 1) menyatakan pengkajian terhadap teks-teks atau yang disebut kajian filologi bertujuan untuk menemukan bentuk asli atau semula dengan cara menyisihkan kesalahankesalahan yang dapat ditemukan dalam teks.

Melihat dari penelitian sebelumnya yang berjudul "Geguritan Ni Sumala Satu Kajian Sosiologi Sastra" oleh I Ketut Nuarca pada tahun 2017. Terlihat jelas perbedaan penelitian jika dilihat dari variasi naskah dan isi teks yang akan digunakan. Penelitian ini sangat berbeda karena bertujuan untuk mengupas tidak hanya melalui isi tetapi melihat dari varian teks dan naskah secara lebih rinci.

Kajian yang digunakan dalam meneliti Geguritan Ni Sumala berupa kajian filologis. Berdasarkan pengetahuan penulis, belum ada teks dan terjemahan dari Geguritan Ni Sumala yang berdasarkan edisi teks secara kritik. Teks Geguritan Ni Sumala akan diteliti lebih lanjut dengan judul "Geguritan Ni Sumala Kajian Filologis”.

\section{METODE DAN TEORI}

Penggunaan metode penelitian dalam kajian ini secara garis besar dapat dibagi menjadi tiga tahap (Galang Nova: 2020, 403) yang akan dipaparkan berikut ini. 
Melalui tahap penyajian data, diawali dengan mengumpulkan data melalui metode observasi dibantu teknik catat serta saat berbagai variasi naskah sudah ditemukan dilanjutkan dengan metode simak yakni membaca teks Geguritan Ni Sumala secara berulangulang. (Sudaryanto, 2015 : 204)

Selanjutnya, tahap analisis data menggunakan metode deskriptif komparatif yakni membandingkan tiga varian dari naskah Geguritan Ni Sumala disertai informasi mengenai keadaan secara fisik dan non fisik dari naskah yang akan diteliti (Ratna, 2012: 53). Langkah berikutnya mengadakan transliterasi dengan metode transliterasi standar, dilanjutkan dengan perbandingan ketiga teks melalui kritik teks, edisi teks menggunakan metode landasan (legger). Terakhir, untuk proses terjemahan menggunakan metode kombinasi terjemahan harfiah dan terjemahan idiomatis, disertai teknik terjemahan terpisah.

Tahap penyajian hasil analisis data menggunakan metode formal dan informal dengan teknik deduktif induktif. Penyajian edisi teks juga dibantu teknik paparan, tabel, dan stema.

Adapun sumber data yang digunakan dalam penelitian ini berupa 3 buah naskah Geguritan Ni Sumala yakni Naskah Geguritan Ni Sumala Koleksi Kantor Dokumentasi Kebudayaan Provinsi Bali (Naskah A), Naskah Geguritan Ni Sumala Koleksi Kantor Dokumentasi Kebudayaan Provinsi Bali (Naskah A), Naskah Geguritan Ni Sumala Koleksi Gedong Kirtya Singaraja (Naskah B), Naskah Geguritan Ni Sumala oleksi Kantor Dokumentasi Kebudayaan Provinsi Bali (Naskah C),

Kata filologi berarti 'cinta ilmu dan sastra' memiliki arti yang sangat luas. Namun pada masa sekarang maknya dipersempit menjadi studi yang berkaitan dengan sastra dan naskah lama. Untuk mempermudah dalam memahami teksteks penting dan kuno yang tersebar di Nusantara maupun dunia, para filolog harus melakukan kritik teks secara mendalam dan melakukan usaha transliterasi. (Ikram, 2019: 41).

Sasaran kerja dari objek kajian filologi adalah naskah. Media berupa naskah ini menggunakan tulisan tangan juga diimbangi dengan teks sebagai objek dari kajian filologi itu sendiri. Teks sebagai kandungan dari naskah merupakan jalan bagi seorang filolog untuk menemukan berbagai infomasi yang terkandung di dalam naskah. (Baried, 1994 : 6)

Menurut Robson (1994: 12), tugas pertama dari seorang filolog adalah mencari bahan mentah berwujud naskah. Selanjutnya, ditentukan metode yang bisa digunakan dalam mengkaji setiap varian teks. Penyajian dan interpretasi tersebut harus ditempatkan dalam satu bagian yang disebut edisi teks.

Kritik teks juga memegang peranan penting dalam kajian filologi. Dalam usaha menemukan teks dalam bentuk aslinya, permasalahan muncul karena sifat keterbukaan teks tersebut sehingga memberikan peluang kebebasan yang cukup besar kepada para penyalin agar bisa menjadi pengarang kedua. Munculnya perubahan yang disengaja maupun tidak bergantung pada faktor zaman teks itu diciptakan ataupun disalin. (Ikram, 2019: 50)

Batasan Filologi Tradisional memiliki kecenderungan untuk berusaha menemukan bentuk awal teks atau sekurang-kurangnya melakukan rekontruksi teks agar mendekati bentuk aslinya. Berbanding terbalik dengan Filologi Modern yang lebih bertujuan untuk menemukan makna kreativitas penyalin yang tampak dalam versi teks yang ditemukan.

Berdasarkan uraian di atas, maka dalam penelitian terhadap teks Geguritan 
Ni Sumala menggunakan teori filologi tradisional yang dilakukan dengan cara melakukan kritik teks terhadap naskah yang ditemukan agar mendekati teks aslinya dan menyajikan teks tersebut sehingga dapat terhindar dari kesalahan.

\section{HASIL DAN PEMBAHASAN}

\section{Kritik Teks Geguritan Ni Sumala}

Salah satu langkah dalam melakukan suntingan naskah adalah melalui kritik teks untuk berusaha mengembalikan teks ke bentuk aslinya sesuai dengan yang diciptakan. (Baried, 1985: 97)

Melalui penelitian ini, ketiga naskah GNS akan dibandingkan, karena penulis menyadari bahwa naskah-naskah dapat diasumsikan mengalami beberapa kali penyalinan. Proses penyalinan naskah GNS tentunya disertai dengan perubahan salin atau tulis oleh penyalinnya. Selain itu, jenis maupun jumlah kesalahan salin atau tulis antara naskah satu dengan yang lain tidak sama.

Berdasarkan kritik teks di atas dengan cara membandingkan ketiga varian naskah GNS, maka diketahui bahwa jenis dan jumlah kesalahan salin/tulis yang dimiliki ketiga naskah GNS tidak sama. Naskah A memiliki kesalahan salin/tulis sebanyak (37), naskah B sebanyak (102), serta naskah C sebanyak (52) kesalahan salin/tulis. Adapun uraian kesalahan salin/tulis seperti berikut ini:

\begin{tabular}{llccc}
\hline No. & JENIS KESALAHAN SALIN/TULIS & \multicolumn{3}{c}{ NASKAH } \\
\cline { 3 - 5 } & & $\mathrm{A}$ & $\mathrm{B}$ & $\mathrm{C}$ \\
\hline 1. & Subsitusi & 19 & 34 & 24 \\
2. & Adisi & 5 & 24 & 5 \\
3. & Omisi & 3 & 16 & 8 \\
4. & Lakuna & 5 & 10 & 5 \\
5. & Interpolasi & 1 & 12 & 2 \\
6. & Ditografi & 1 & 0 & 1 \\
7. & Transposisi & 2 & 5 & 2 \\
8. & Korup & 1 & 1 & 5 \\
\hline & & 37 & 102 & 52 \\
\hline
\end{tabular}

Berdasarkan perbandingan naskah melalui kritik teks di atas, maka ketiga naskah (A, B dan C) diklasifikasikan menjadi dua kelompok. Kelompok pertama adalah naskah A dan C sedangkan kelompok kedua hanya naskah B. Pengelompokan didasarkan atas pertimbangan bahwa naskah $\mathrm{A}$ dan $\mathrm{C}$ memiliki jumlah varian atau kesalahan salin/tulis lebih kecil dibandingkan dengan naskah $\mathrm{B}$.

Perbandingan juga dapat dilihat dari jumlah bait dari ketiga naskah. Naskah A dan $\mathrm{C}$ memiliki jumlah bait yang sama sebanyak 220 bait, sedangkan jumlah bait naskah B adalah sebanyak 205 bait. Jika dilihat dari kandungan isi cerita, naskah A dan $\mathrm{C}$ memiliki persamaan cerita dari bagian awal hingga akhir. Pada naskah $\mathrm{B}$ awal cerita tidaklah sama dengan kedua naskah lainnya. Ada kemungkinan bahwa naskah $\mathrm{A}$ dan $\mathrm{C}$ tidak disalin dari naskah $B$ begitu pula sebaliknya.

Hasil kritik teks di atas menunjukkan 
bahwa naskah A secara umum memiliki kualitas yang lebih unggul dibandingkan dengan naskah GNS yang lain. Hal ini terlihat dari jumlah kesalahan salin tulis pada naskah A lebih sedikit dari dua naskah lainnya yakni B dan C. Yang menjadi landasan dalam edisi teks adalah naskah A.

\section{Edisi Teks dan Terjemahan Geguritan Ni Sumala}

GNS merupakan salah satu hasil karya sastra Bali tradisional dalam bentuk geguritan yang ditulis menggunakan aksara Bali dan menggunakan bahasa Bali Kawi. Sebagai dasar penyusunan edisi teks, alih aksara dan ejaan merupakan salah satu aspek yang penting dalam kajian ini. Adapun pedoman yang digunakan dalam transliterasi dari aksara Bali ke aksara latin adalah sesuai dengan pendapat Acri dan Griffiths (2014: 371-372) dikombinasikan dengan pendapat Damais (1995: 125).

Ejaan yang dipakai dalam penyusunan edisi teks adalah menggunakan Pedoman Ejaan Bahasa Bali dengan Huruf Latin dan Huruf Bali yang disusun oleh I Nengah Tinggen, diterbitkan oleh Lembaga Bahasa Nasional di Singaraja pada tahun 1972. Pedoman lain yang digunakan berkaitan dengan aksara Bali adalah Pedoman Pasang Aksara Bali yang diterbitkan oleh Dinas Kebudayan Provinsi Bali pada tahun 2005 di Denpasar.

Adapun cara membaca catatan kaki yang terdapat dalam edisi teks GNS melalui beberapa contoh seperti di bawah ini:

1) 2.3.1. Inggih, C. 2. Gempalan, C.

Keterangan:

$2=$ bait

$3=$ baris/larik

1. Inggih, $\mathrm{C}=$ Kesalahan salin/tulis pertama pada bait kedua dan baris ketiga adalah kata inggih pada naskah A diangkat dalam edisi teks.

3. Gempalan, $\mathrm{C}=$ Kesalahan salin/tulis pertama pada bait kedua dan baris ketiga adalah kata gempalan pada naskah $\mathrm{C}$. Karena kata tersebut dianggap salah, maka kata gagempalan pada naskah A diangkat dalam edisi teks.

2) 27.1.1. (lakuna), A,C; 7.(2-2). Pancoran besi punika, B.

Keterangan:



1. (lakuna), A,C. = Kesalahan salin/tulis pertama pada bait ke-27 baris pertama adalah pada naskah $\mathrm{A}$ dan $\mathrm{C}$ (terjadi lakuna). Hal ini menyebabkan kata yang tertulis pada naskah B diangkat dalam edisi teks.

(2-2). Pancoran besi punika, B. = Kesalahan salin/tulis kedua pada bait ke27 baris ketujuh adalah frase pancoran besi punika pada naskah B. Karena frase tersebut dianggap salah, maka frase yang diangkat dalam edisi teks adalah besi pancoran punika sesuai dengan naskah A dan C.

Selanjutnya, terjemahan teks GNS ke dalam bahasa Indonesia tidak sematamata menggunakan terjemahan harfiah, namun diimbangi dengan kata bahasa Indonesia yang sepadan pula (Larson, 2005: 39). Hambatan dalam mencari padanan yang sesuai juga menyebabkan terjemahan agak janggal sehingga akan ditambahkan kata-kata yang tidak ada dalam teks untuk kelancaran terjemahan (Sardjono, 1986: 17)

Cara penyajian terjemahan dapat dibedakan menjadi tiga jenis yakni: 1) secara interlinear yaitu teks terjemahan ditempatkan di bawah teks aslinya; 2) secara berdampingan yaitu teks terjemahan ditempatkan disamping di samping kanan teks asli; 3) teks terjemahan yang ditempatkan dalam subbab terpisah. Dari ketiga cara 
penyajian tersebut, terjemahan teks GNS akan ditempatkan menggunakan cara ke3 dengan menyajikan seluruh teks sumber terlebih dahulu disusul dengan teks terjemahan pada subbab berikutnya. Proses penerjemahan ditunjang oleh Kamus Bali-Indonesia edisi ke-3 oleh Balai Bahasa Bali (2016) dan Kamus Jawa Kuno-Indonesia P.J. Zoetmulder bekerja sama dengan S.O. Robson (1995)

\section{SIMPULAN}

Geguritan Ni Sumala dalam bentuk karya sastra geguritan yang menggunakan Bahasa Kawi Bali. Dilihat dari aturan padalingsa, geguritan ini menggunakan dua jenis pupuh yakni sejumlah 187 bait Pupuh Ginada dan 33 bait Pupuh Adri. Berkaitan dengan penelitian ini, penulis mengunakan tiga buah naskah Geguritan Ni Sumala yang berasal dari tiga tempat penyimpanan naskah berbeda di Bali.

Adapun perbedaan terhadap ketiga naskah GNS dapat dilihat dari perspektif kritik teks. Kesalahan salin/tulis yang ditemukan pada masing-masing naskah berbeda dari segi jenis ataupun jumlah kesalahan salin/tulis. Naskah A memiliki kesalahan salin/tulis seperti: Substitusi (19), Adisi (5), Omisi (3), Lakuna (5), Interpolasi (1), Ditografi (1), Transposisi (2), Korup (1) dengan total keseluruhan sebanyak 37. Jika ditinjau dari naskah B, adapun rincian kesalahan salin/tulis adalah: Substitusi (34), Adisi (24), Omisi (16), Lakuna (10), Interpolasi (12), Transposisi (5), Korup (1). Secara keseluruhan, jumlah kesalahan salin/tulis pada naskah B adalah sebanyak 102 . Naskah C memiliki 52 kesalahan salin/tulis dengan penjabaran: Substitusi (24), Adisi (5), Omisi (8), Lakuna (5), Interpolasi (2), Ditografi (1), Transposisi (2), Korup (5).

Materi yang dipilih untuk edisi teks GNS adalah naskah A yakni naskah Geguritan Ni Sumala koleksi Dinas
Kebudayaan Provinsi Bali dengan menerapkan metode landasan (legger) dengan anggapan bahwa materi ini memiliki penyaksi terbanyak. Menurut Simpen (2005: 4), tidak menutup kemungkinan penyaksi yang berjumlah sedikit juga bisa menjadi bahan dalam edisi teks jika memenuhi syarat misalnya dalam geguritan sesuai dengan aturan terikat berupa guru wilangan atau guru dingdong.

Langkah terakhir dalam penelitian ini adalah menyajikan terjemahan yang didahului oleh teks sumber pada subbab sebelumnya dengan menggunakan bahasa Indonesia. Melalui variasi teks yang telah dikaji, dijumpai berbagai bahasa arkais khususnya bahasa Bali yang layak untuk dijadikan sebagai bahan penelitian berikutnya.

\section{DAFTAR PUSTAKA}

Acri, A., \& Griffiths, A. (2014). "The Romanisation of Indic Script used in Ancient Indonesia", Journal of the Humanities and Social Sciences of Southeast Asia, Vol. 170, No. 23.

Baried, S. B. (1985). Pengantar Teori Filologi. Jakarta: Pusat Pembinaan dan Pengembangan Bahasa.

Baried, S. B. (1994). Pengantar Teori Filologi. Jakarta: Pusat Yogyakarta: Pusat Pengembangan dan Publikasi Seksi Filologi, Fakultas Sastra Universitas Gadjah Mada.

Damais, L. C. (1995). Epigrafi dan Sejarah Nusantara. Jakarta: Pusat Penelitian Arkeologi Nasional.

Galang Nova, I Putu. (2020). “Analisis Ideologi pada Teks Mitos Baris Cina di Desa Adat Renon", 
Humanis. Vol 24, No. 4.

Ikram, Achadiati. (2019). Pengantar Penelitian Filologi. Jakarta: Masyarakat Pernaskahan Nusantara (Manassa).

Larson, M. L. (2005). Penerjemahan Berdasar Makna: Pedoman untuk Pemadanan Antarbahasa. Jakarta: ARCAN.

Nuarca, Ketut. (2017). Geguritan Ni Sumala Satu Kajian Sosiologi Sastra. Denpasar: Universitas Udayana.

Ratna, N. K. (2012). Penelitian Sastra: Teori, Metode, dan Teknik. Yogyakarta: Pustaka Pelajar.

Robson, S. O. (1978). Bahasa dan Sastra: Pengkajian Sastra-Sastra Tradisional Indonesia. Jakarta: Pusat Pembinaan dan Pengembangan Bahasa.

Sardjono, Partini. (1986). Kakawin Gajah Mada Sebuah Karya Sastra Kakawin Abad ke-20: Suntingan Naskah serta Telaah Struktur, Tokoh dan Hubungan Antarteks. Bandung: Binacipta.

Simpen, A. B. Wayan. (2005). Pedoman Pasang Aksara Bali. Denpasar: Dinas Kebudayaan Provinsi Bali.

Sudaryanto, D. P. (2015). Metode dan Teknik Analisis Bahasa. Yogyakarta: Duta Wacana University.

Tinggen, I. N. (1972). Pedoman Ejaan Bahasa Bali dengan Huruf Latin dan Huruf Bali. Singaraja: Lembaga Bahasa Nasional. 